\title{
Perception of Players towards National Sports Council**
}

\author{
Madhav Kumar Shrestha ${ }^{1}$ \\ Visiting Faculty \\ Department of Education and Social Science \\ Janamaitri Multiple Campus, Kuleshwar, Kathmandu, Nepal \\ Email: lunumadhav@hotmail.com
}

Sarala Karki ${ }^{2}$

Peer Reviewed by : Prof. Dr. Shyam Krishna Maharjan

Prof. Dr. Bhimsen Devkota

\begin{abstract}
This study entitled "Perception of players towards National Sports Council", aimed to find out the perception of players towards National Sports Council, and to describe and analyze the perception of players towards National Sports Council. The necessary information was taken from different players and member of National Sports Council. Altogether, there were one hundred and fifty respondents selected from different games and members of National Sports Council. The main source of data was primary. The researchers used ready-made tools made by Carr, where eleven statements were involved to gather data. There were diverse perceptions towards games and sports in Nepal. Among 150 respondents 56 (37.3\%) expressed strongly disagree, 83 (55.3\%) disagree, $02(01.3 \%)$ undecided, 6 (4\%), agree and 3 (2\%) strongly agree on the statement "National Sports Council manage proper training and coaching program for players."
\end{abstract}

Keywords: Perception, National Sports Council, Training, Coaching, Physical education.

\section{Background of the study}

Physical activities and sports program emphasized physical fitness and attained through formal exercises (Bucher, 1979). Students moved around in formal line and were required to strictly follow a large number of rules. Today, physical education and sports program reflect a more humanistic approach. Curriculum are more students centered,

1 Corresponding author: Lecturer of Sanothimi Campus, Sanothimi, Bhaktapur

2 Co-investigator: Student of Sanothimi Campus.

** This research is funded by University Grant Commission, Sanothimi, Bhaktapur 
programs are more individual as teachers realized as one type of physical education and sports program is not suited to all individuals (Freeman, 1988). The feelings, needs, ambitions, goals, capabilities and limitations should be considered in designing the program.

When the National Education System Plan (NESP 2028 B. S.) was introduced in Nepal, it emphasized a policy of uniform curriculum plan throughout the country associating physical education and sports. Gradually with the development of education, the College of Education began Health and Physical Education in teacher education program as a major subject in Intermediate of Education and Bachelor of Education level and later the revised curriculum made a policy to provide physical education as an extra optional subject. The school curriculum was further modified and even in the changed curriculum Health and Physical Education was introduced as a compulsory subject from grade one to eight as an optional subject in grade nine and ten in $2049 \mathrm{~B}$. S.

National Sports Council was established in 2015 B. S. as the first sports organization of Nepal. Initially, its name was "Health and Sports Council". It was then changed into Sports Council in 2017 B. S. The Sports Act of 2021 B. S. reformed the Sports Council to the National Sports Council (Maharjan and Adhikari, 2065).

National Sports Council in association with the Government of Nepal is contributing in developing physical education, games and sports in Nepal. The main objective of National Sports Council is to produce good players and develop games and sports in Nepal. It trains coaches and sends them in foreign countries for further training. Beside, many sports associations are affiliated with the Sports Council, which have taken various responsibilities such as selection and training of players, training and production of coaches, conduction of tournaments, inviting foreign instructors and coach, sending the player to participate at various level of tournaments in the country and out of country (Baruwal et al., 2065).

\section{Objectives of the Study}

- To find out the perception of players towards National Sports Council

- To analyze the perception of players towards National Sports Council according to different variables

\section{Review of Related Literature}

Games and sports are considered one of the most important health markers and a predictor of morbidity and mortality, for cardiovascular disease (WHO: Geneva, 2010). Therefore, the promotion of games and sports plays an important role in minimizing the development of chronic diseases of lifestyle (Min-Lee et al., 2012). In addition, it aids in injury prevention and contributes to quality of life and psychological health. 
Bullock and Alden (1933) investigated the factors that were causing an unfavorable reaction to physical education. A questionnaire was administered to 192 freshman women. Results showed that of those sampled 63.6\% liked physical education and $36.4 \%$ disliked it. Interestingly many of the students, who disliked physical education, were previously taught by an untrained high school physical education teacher.

Rai (2005) had undertaken a study on "A comparative study on teacher attitude towards physical education." The data were collected through the Adams physical education attitude scale of attitude test from 52 respondents of different schools. Forty questions and twenty eight statements were administered for Adams scale. It was concluded in the private school which have offered health and physical education have been teaching physical education by non-specialist teachers. They were generally trained in sports and games. The investigator also found that the respondent had positive attitude towards the physical education.

Sedai (2005) studied on, "A study of attitude towards physical education of studying in Bachelor's Degree in education." His main purpose was to find out the student's attitude towards physical education. Applying readymade tools from Adams scale was use to collect the data. It concluded that all respondents had positive attitude towards the physical education.

\section{Methodology}

The researcher employed descriptive quantitative research design. The populations of this study were 150players and member of National Sports Council selected from purposive sampling method. Researcher had applied Likert Scale type's questionnaires. The questionnaires were rated as follows: 1-strongly agree, 2-agree, 3-undicided, 4-disagree and 5-strongly disagree. The frequencies of respondent's responses were analyzed to establish their true feelings about perceptions.

\section{Analysis and discussion of result}

Perception is a mental or neural state of readiness, organized through experience, exerting a directive or dynamic influence on the individual's response to all objects and situations (Allport, 1935). A simpler definition of perception is a mindset or a tendency to act in a particular way due to both an individual's experience and temperament. Typically, when we refer to a person's perception, we are trying to explain his or her behavior. Perceptions are complex combination of things we tend to call beliefs, values, behaviors, and motivations. 
Table 1: Promotion of games and sports

\begin{tabular}{|c|c|c|c|c|c|}
\hline \multirow{2}{*}{ Symbol } & \multicolumn{4}{|c|}{ Sex of the Respondents } & \multirow{2}{*}{ Total \% } \\
\cline { 2 - 5 } & Male & Percent & Female & Percent & \\
\hline SA & 2 & 01.3 & 00 & 00 & 01.3 \\
\hline A & 12 & 08.0 & 08 & 05.3 & 13.3 \\
\hline U & 5 & 03.3 & 01 & 0.7 & 04 \\
\hline D & 57 & 38.0 & 23 & 15.3 & 53 \\
\hline SD & 26 & 17.3 & 16 & 10.7 & 28.0 \\
\hline Total & 103 & 68.7 & 47 & 31.3 & 100 \\
\hline
\end{tabular}

Note:- $S A=$ Strongly Agree, $A=$ Agree, $U=$ Undecided, $D=$ Disagree and $S D=$ Strongly Disagree.

Table 1 shows that among 150 respondents $42(28.0 \%)$ expressed strongly disagree, 80 $(53.3 \%)$ disagree, $05(03.3 \%)$ undecided, $20(13.3 \%)$ agree and $02(01.3 \%)$ strongly agree on the statement National Sports Council plays a vital role to promote games and sports in Nepal. So, it can be interpreted that National Sports Council could not play a vital role to promote games and sports in Nepal.

Table 2: Facilities and equipment for games and sports

\begin{tabular}{|c|c|c|c|c|c|}
\hline \multirow{2}{*}{ Symbol } & \multicolumn{4}{|c|}{ Sex of the Respondents } & \multirow{2}{*}{ Total \% } \\
\cline { 2 - 5 } & Male & Percent & Female & Percent & \\
\hline SA & 2 & 1.3 & 00 & 00 & 1.3 \\
\hline A & 7 & 4.7 & 00 & 00 & 4.7 \\
\hline U & 1 & 0.7 & 00 & 00 & 0.7 \\
\hline D & 71 & 47.3 & 23 & 15.3 & 62.7 \\
\hline SD & 22 & 14.7 & 24 & 16 & 30.7 \\
\hline Total & 103 & 68.7 & 47 & 31.3 & 100 \\
\hline
\end{tabular}

Table 2 shows that out of 150 respondents 46 (30.7\%) strongly disagree, 94 (62.7\%) disagree, $01(0.7 \%)$ undecided, $07(04.7 \%)$ agree and $02(01.3 \%)$ strongly agree on the statement "National Sports Council provides sufficient facility and equipment for practicing a games and sports."

Table 3: Management of training and coaching program

\begin{tabular}{|c|c|c|c|c|c|}
\hline \multirow{2}{*}{ Symbol } & \multicolumn{4}{|c|}{ Sex of the Respondents } & \multirow{2}{*}{ Total \% } \\
\cline { 2 - 5 } & Male & Percent & Female & Percent & \\
\hline SA & 03 & 2.00 & 00 & 00 & 2.00 \\
\hline A & 06 & 4.00 & 00 & 00 & 4.00 \\
\hline U & 01 & 0.7 & 01 & 0.7 & 01.3 \\
\hline D & 54 & 36.00 & 29 & 19.3 & 55.3 \\
\hline
\end{tabular}




\begin{tabular}{|c|c|c|c|c|c|}
\hline SD & 39 & 26 & 17 & 11.3 & 37.3 \\
\hline Total & 103 & 68.7 & 47 & 31.3 & 100 \\
\hline
\end{tabular}

Table 3 shows that out of 150 respondents 56 (37.3\%) expressed strongly disagree, 83 $(55.3 \%)$ disagree, $02(01.3 \%)$ undecided, $06(04.0 \%)$ agree and $03(02 \%)$ strongly agree on the statement "National Sports Council manages proper training and coaching program for players".

Cumulatively, 92.6 percent respondents responded negatively that National Sports Council manages proper training and coaching program for players. So, it can be interpreted that National Sports Council could not manage training and coaching program for players to improve sports performance and games strategies.

Table 4: Management of trainers and coaches

\begin{tabular}{|c|c|c|c|c|c|}
\hline \multirow{2}{*}{ Symbol } & \multicolumn{4}{|c|}{ Sex of the Respondents } & \multirow{2}{*}{ Total \% } \\
\cline { 2 - 5 } & Male & Percent & Female & Percent & \\
\hline SA & 20 & 13.3 & 00 & 00 & 13.3 \\
\hline A & 19 & 12.7 & 00 & 00 & 12.7 \\
\hline U & 01 & 0.7 & 00 & 00 & 0.7 \\
\hline D & 42 & 28 & 14 & 09.3 & 37.3 \\
\hline SD & 21 & 14 & 33 & 22 & 54 \\
\hline Total & 103 & 68.7 & 47 & 31.3 & 100 \\
\hline
\end{tabular}

Table 4 shows that among 150 respondents 54 (36.0\%) expressed strongly disagree, 56 (37.3\%) disagree, $01(0.7 \%)$ undecided, $19(12.7 \%)$ agree and $20(13.3 \%)$ strongly agree on the statement "National Sports Council manages qualified and experienced trainers and coaches". So, it can be interpreted that National Sports Council could not manage qualified and experienced trainers and coaches in training and coaching program.

Table 5: Incentive and reinforcement for players

\begin{tabular}{|c|c|c|c|c|c|}
\hline \multirow{2}{*}{ Symbol } & \multicolumn{4}{|c|}{ Sex of the Respondents } & \multirow{2}{*}{ Total \% } \\
\cline { 2 - 5 } & Male & Percent & Female & Percent & \\
\hline SA & 00 & 00 & 01 & 0.7 & 0.7 \\
\hline A & 07 & 04.7 & 04 & 02.7 & 07.3 \\
\hline U & 05 & 03.3 & 07 & 04.7 & 08.0 \\
\hline D & 38 & 25.3 & 20 & 13.3 & 38.7 \\
\hline SD & 53 & 35.3 & 15 & 10 & 45.3 \\
\hline Total & 103 & 68.7 & 47 & 31.3 & 100 \\
\hline
\end{tabular}

Table 5 shows that out of 150 respondents $68(45.3 \%)$ expressed strongly disagree, $58(38.7 \%)$ disagree, $12(8.0 \%)$ undecided, $11(07.3 \%)$ agree and $01(0.7 \%)$ strongly 
agree on the statement "National Sports Council provides sufficient incentive and reinforcement for players timely". It can be interpreted that National Sports Council could not provide sufficient incentive and reinforcement for players.

Table 6: Health service and insurance for players

\begin{tabular}{|c|c|c|c|c|c|}
\hline \multirow{2}{*}{ Symbol } & \multicolumn{4}{|c|}{ Sex of the Respondents } & \multirow{2}{*}{ Total \% } \\
\cline { 2 - 5 } & Male & Percent & Female & Percent & \\
\hline SA & 03 & 02 & 01 & 0.7 & 02.7 \\
\hline A & 02 & 01.3 & 02 & 01.3 & 02.7 \\
\hline U & 01 & 0.7 & 02 & 01.3 & 02 \\
\hline D & 51 & 34 & 25 & 16.7 & 50.7 \\
\hline SD & 46 & 30.7 & 17 & 11.3 & 42 \\
\hline Total & 103 & 68.7 & 47 & 31.3 & 100 \\
\hline
\end{tabular}

Table 6 shows that among 150 respondents 63 (42.0\%) expressed strongly disagree, 76 $(50.7 \%)$ disagree, $03(2.0 \%)$ undecided, $04(02.7 \%)$ agree and $04(02.7 \%)$ strongly agree on the statement "National Sports Council manages proper health service and health insurance for players". It can be interpreted that National Sports Council could not manage sufficient and effective health service and insurance for players during sports competitions.

Table 7: Diet and salary for players

\begin{tabular}{|c|c|c|c|c|c|}
\hline \multirow{2}{*}{ Symbol } & \multicolumn{4}{|c|}{ Sex of the Respondents } & \multirow{2}{*}{ Total \% } \\
\cline { 2 - 5 } & Male & Percent & Female & Percent & \\
\hline SA & 00 & 00 & 02 & 01.3 & 01.3 \\
\hline A & 00 & 00 & 02 & 01.3 & 01.3 \\
\hline U & 00 & 00 & 01 & 0.7 & 0.7 \\
\hline D & 62 & 41.3 & 29 & 19.3 & 60.7 \\
\hline SD & 41 & 27.7 & 13 & 08.7 & 36 \\
\hline Total & 103 & 68.7 & 47 & 31.3 & 100 \\
\hline
\end{tabular}

Table 7 shows that out of 150 respondents 54 (36.0\%) expressed strongly disagree, 91 $(60.7 \%)$ disagree, $01(0.7 \%)$ undecided, $02(01.3 \%)$ agree and $02(01.3 \%)$ strongly agree on the statement "National Sports Council manages proper health service and health insurance for players". So, it can be interpreted that National Sports Council could not manage and provide sufficient and effective health service and insurance for players during sports competitions. 
Table 8: Fairness in the Process of player selection

\begin{tabular}{|c|c|c|c|c|c|}
\hline \multirow{2}{*}{ Symbol } & \multicolumn{4}{|c|}{ Sex of the Respondents } & \multirow{2}{*}{ Total \% } \\
\cline { 2 - 5 } & Male & Percent & Female & Percent & \\
\hline SA & 06 & 04 & 02 & 01.3 & 05.3 \\
\hline A & 44 & 29.9 & 23 & 15.3 & 44.7 \\
\hline U & 08 & 5.3 & 05 & 03.3 & 8.7 \\
\hline D & 30 & 20 & 12 & 08 & 28.0 \\
\hline SD & 15 & 10 & 05 & 3.3 & 13.3 \\
\hline Total & 103 & 68.7 & 47 & 31.3 & 100 \\
\hline
\end{tabular}

Table 8 shows that among 150 respondents 63 (42.0\%) expressed strongly disagree, 76 (50.7\%) disagree, $03(2.0 \%)$ undecided, $04(02.7 \%)$ agree and $04(02.7 \%)$ strongly agree on the statement "National Sports Council manages proper health service and health insurance for players". It can be interpreted that National Sports Council could not manage sufficient and effective health service and insurance for players during and after the sports competitions.

Table 9: Organizing competition according to schedules

\begin{tabular}{|c|c|c|c|c|c|}
\hline \multirow{2}{*}{ Symbol } & \multicolumn{4}{|c|}{ Sex of the Respondents } & \multirow{2}{*}{ Total \% } \\
\cline { 2 - 5 } & Male & Percent & Female & Percent & \\
\hline SA & 08 & 05.3 & 01 & 0.7 & 06.0 \\
\hline A & 31 & 20.7 & 00 & 00 & 20.7 \\
\hline U & 17 & 11.7 & 07 & 4.7 & 16.0 \\
\hline D & 38 & 25.3 & 37 & 24.7 & 50.0 \\
\hline SD & 09 & 06 & 02 & 1.3 & 07.3 \\
\hline Total & 103 & 68.7 & 47 & 31.3 & 100 \\
\hline
\end{tabular}

Table 9 shows that out of 150 respondents $11(07.3 \%)$ expressed strongly disagree, 75 $(50.0 \%)$ disagree, 24 (16.0\%) undecided, $31(20.7 \%)$ agree and 09 (06.0 \%) strongly agree on the statement "National Sports Council could organize sports competition according to schedules". It can be interpreted that National Sports Council could not organize games and sports competitions according to national schedule.

\section{Conclusion}

Physical inactivity is a modifiable risk factor for cardiovascular disease and a widening variety of other chronic diseases, including diabetes, obesity, hypertension, bone and joint diseases and depression. There were differences in perceptions towards games and sports in Nepal. Among 150 respondents 68 (45.3\%) expressed strongly disagree, 58 $(38.7 \%)$ disagree, $12(8.0 \%)$ undecided, $11(07.3 \%)$ agree and $01(0.7 \%)$ strongly agree on the statement "National Sports Council provides sufficient incentive and reinforcement for players timely" 
The National Sports Council started organizing National level sports competitions from 2038 BS. These are construction of physical facilities, management of sports equipment, conduction of training and coaching program, conduction of National and International sports competitions, selection of players, invitation of foreign coaches and trainers, production of coach and other officials. But respondents' responses are seen mostly negative about National Sports Council.

\section{Acknowledgement}

This research was funded by the university grand commission (UGC) under the small RDI grant 2073/74 awarded to Madhav Kumar shrestha and Sarala Karki. S0, first of all I would like to extend our profound gratitude to University Grant Commission, Sanothimi, Bhaktapur for providing us an opportunity to conduct a small research project.

\section{References}

Allport, G. W. (1935). Handbook of social psychology. Worcester: Clark University Press

Backford, P. A. (1976). "A normative study of the physical fitness of 15 and 16 years old Navajo girls." Completed research in health, physical education and recreation 14-159

Barry, C. J. and Nelson. J. K. (1988). Practical measurement for evaluation in physical education. Delhi: Surjeet Publication, 7- K, Kolhapur Road.

Baruwal, H. B. et al. (2065). Foundation of physical education and game. Kathmandu: Pinnacal Publication, Bagbazar.

Bucher, C. A. (1979). Foundations of physical education. London: The C. V. Mosby Company.

Bullock, M., \& Alden, F. D. (1933). 'Some of the factors determining theattitude of freshman women at the University of Oregon toward requiredphysical education.' Research Quarterly, 4 (4), 60-64.

Council, N. S. (2065). Fifth National game smarika. Kathmandu: National Sports Council.

Dangi, K. (2012, march 5). 'APF defends football title.' The Kathmandu post daily, p. 11.

Dwyer, T. (1996). 'Physical activity and performance in children.' Nutrition Reviews, 54, S27-S31.

Maharjan, R. K. \& Adhikari, P. (2065). Foundation of physical education. Kathmandu: Sunlight Publication.

Pandey, S. \& Poudel, S. (2053). Khelkudgyanmanch. Kathmandu: Prawesh Prakashan.

Rai, S. (2005). "A Comparative Study on Teachers Attitude towards Physical Education." An unpublished master degree thesis, submitted to health, physical and Population education department, T. U. Kritipur.

Shrestha, M. K. (2006). "Analysis of sports attitude of secondary school student in Kathmandu district." An unpublished master degree thesis, submitted to Health, Physical and Population Education Department, T.U, Kritipur

Upadhyaya, S. P. (2002). History of Nepalese participation in Olympic Games in Nepal. Kathmandu: Nepal Olympic Committee.

World Health Organization (2010). Global recommendations on physical education for health. WHO: Geneva. 